\title{
The Incidence and Management of Urethral Stricture in Bladder Carcinoma
}

\author{
Reyad Ahmed Farhood (FIBM (URO) $)^{1}$, Othman Jasim Mohammed Alzaidy \\ $(\text { FIBM }(\text { URO }))^{2}$ and Aiad Abd Al Hameed Hassen(FIBM (URO) $)^{3}$
}

\footnotetext{
${ }^{1}$ Baquba Teaching Hospital ,Diyala, Iraq

${ }^{2}$ Baquba Teaching Hospital , Diyala, Iraq

${ }^{3}$ Baquba Teaching Hospital, Diyala, Iraq

Correspondence Address:

Dr. Reyad Ahmed Farhood

Baquba Teaching Hospital, Diyala, Iraq

email: Reyad3333@yahoo.com mobile 009647705892298
}

Received: 20 September 2020

Revised: 24 September 2020

Accepted: 28 September 2020

Published: 15 April 2021

Diyala Medical Journal 2021:20(1): 76- 82

\begin{abstract}
Background: Urethral stricture disease is one of the oldest and most difficult maladies known to the urologist. While references to the disease and its treatment date back to the writings of the Hindus, Egyptians, and Greeks.

Objective: To elicit the incidence of urethral strictures, their severity and management in patients with superficial bladder tumor.

Patients and Methods: From January 2018 to January 2020, we followed 98 patients admitted and treated at Baquba Teaching Hospital urology unit for having bladder carcinoma. Theywere all male subjects, their age range from 38-76y with a mean 56.8y. They were required to have a cystoscopically and histologically proven superficial transitional cell carcinoma of the bladder to be enrolled in this study (invasive tumors were excluded). For all the patients and after having the cystoscopic diagnosis ,transurethral resection of the tumor done and in most of them this is followed by six week courses of intravesical chemotherapy (either mitomycin or doxorubicin according to the availability). Intravesical Doxorubicin used in 13 cases (56.5\%), Mitomycin C in 6 cases $(26.1 \%)$ and 3 patients $(13.0 \%)$ received both drugs (through multiple courses).while 1 patient $(4.3 \%)$ received no chemotherapy. Thirteen strictures $(56.5 \%)$ were managed by optical urethrotomy while 10 cases $(43.5 \%)$ were mild strictures and opened just by introducing the cystoscope.

Results: During the period of the study, a total of 23 urethral strictures were identified in the 98 male patients with superficial bladder tumor enrolled in this study, which constitutes an incidence of $23.5 \%$ all were diagnosed by the follow -up check cystoscopies . Patient age ranged from 38-75 years with a mean age 59.30+- 10.58. Among those patients with urethral
\end{abstract}


stricture ,14 patients had also B.P.H (60.9\%), but only 7 patients $(30.4 \%)$ had a history of retention of urine. The urethral stricture was bulbar in all patients and it was mild stricture in 10 cases $(43.5 \%)$, moderate in 6 cases $(26.1 \%)$ and severe in 7 cases $(30.4 \%)$. Prior to the diagnosis of stricture , 13 patients had been subjected to a single check cystoscopy $(56.5 \%), 6$ patients $(26.1 \%)$ had twice, while 4 patients $(17.4 \%)$ had 3 or more cystoscopies prior to the occurence of stricture . Regarding intravesical chemotherapy prior to the occurance of stricture ,4 patients (17.4\%) received 1-3 sessions , 10 patients (43.5\%) received 4-6 sessions and 9 patients $(39.1 \%)$ received more than 6 sessions. Intravesical Doxorubicin used in 13 cases (56.5\%), Mitomycin $\mathrm{C}$ in 6 cases $(26.1 \%)$ and 3 patients $(13.0 \%)$ received both drugs (through multiple courses).while 1 patient $(4.3 \%)$ received no chemotherapy. Thirteen strictures $(56.5 \%)$ were managed by optical urethrotomy while 10 cases $(43.5 \%)$ were mild strictures and opened just by introducing the cystoscope.

Conclusion: Urethra stricture in patients with bladder carcinoma may be a substantial source of preventable morbidity, implementing a nursing education program may significantly decrease the incidence of stricture.

Keywords: bladder carcinoma; urethral stricture; Baquba Teaching Hospital

\section{Introduction}

Urethral stricture disease is one of the oldest and most difficult maladies known to the urologist. While references to the disease and its treatment date back to the writings of the Hindus, Egyptians, and Greeks, the management of this disease has undergone significant change in the last 4 decades[1,2]. By definition , anterior urethral disease: is a scarring process involving the spongy erectile tissue of the corpus spongiosum \{spongiofibrosis\} resulting in reduction of the urethral lumen[3]. In contrast posterior urethral strictures; are not included in the common definition of urethral stricture,posterior urethral stricture is an obliterating process in the posterior urethra that has resulted in fibrosis and generally the effect of distraction in the area caused by either trauma or radical prostatectomy[4].

\section{Applied surgical anatomy}

Divided by the perineal membrane the male urethra is composed of posterior (prostatic and membranous) and anterior (bulbous and pendulous) parts. The prostatic urethra, extending from the bladder neck to the apex of prostate and marked by the distal end vermontanum, fixed to the anterior pubic arch by paired puboprostatic ligaments. Here the posterior urethra is particularly vulnerable to direct injury from the displacement of broken rami and torn puboprostatic ligament[5].The membranous urethra is situated between the prostatic apex and the beginning of the proximal corpus spongiosum is considered to be the least supported and protected part of urethra. Forces involved with a pelvic fracture are likely to disrupt the posterior urethra and surrounding active distal sphincter mechanism at this point[6].The bulbous urethra begins where it is enveloped by the corpus spongiosum. It is subsequently encased with the corpus cavernosum by two successive facial layers, the bucks and the 
dartos fascia, a proximately the urethral lumen remains eccentric dorsally in the corpus spongiosum but achieves a central position in the distal pendulous part of the urethra , the bulbous urethra is further defined by the bulbospongiosus muscle which surrounds it ventrally and terminates at the penoscrotal junction where the pendulous urethra begins[7]. The bulbous urethra is more frequently damaged from blunt injuries compared with the pendulous urethra due to its fixation beneath the pubic bone[8].

\section{Patients and Methods}

From January 2018 to January 2020, we followed 98 patients admitted and treated at Baquba Teaching Hospital urology unit for having bladder carcinoma. They were all male subjects, their age range from 3876years with a mean 56.8y. All were required to have a cystoscopically and histologically proven superficial transitional cell carcinoma of the bladder to be enrolled in this study (invasive tumors were excluded). For all the $\mathrm{s}$ and after having the cystoscopic diagnosis ,transurethral resection of the tumor done, and in most of them this is followed by 6-week courses of intravesical chemotherapy (either mitomycin or doxorubicin according to the availability).

\section{Statistical analysis}

The data analysis was performed using descriptive statistics, including frequency, percentage, comparisons where made using Chi $\mathrm{x} 2$ test using standard equations. The result were reported with $\mathrm{p}<0.05$ or $\mathrm{p}<0.01$

\section{Results}

During the period of the study, a total of 23 urethral strictures were identified in the 98 male patients with superficial bladder tumor enrolled in this study, which constitutes an incidence of $23.5 \%$ all were diagnosed by the -up check cystoscopies .Patient age ranged from 38-75 years with a mean age 59.30+10.58 (Table 1). Among those patients with urethral stricture, 14 patients had also benign prostatic hypertrophy $(60.9 \%)$, but only 7 patients $(30.4 \%)$ had a history of retention of urine (table 4). The urethral stricture was bulbar in all patients and it was mild stricture in 10 cases $(43.5 \%)$, moderate in 6 cases $(26.1 \%)$ and severe in 7 cases $(30.4 \%)$ (Table $5)$. Prior to the diagnosis of stricture , 13 patients had been subjected to a single check cystoscopy $(56.5 \%), 6$ patients $(26.1 \%)$ had twice, while 4 patients $(17.4 \%)$ had 3 or more cystoscopies prior to the occurence of stricture (Table 2). Regarding intravesical chemotherapy prior to the occurence of stricture ,4 patients (17.4\%) received 1-3 sessions , 10 patients $(43.5 \%)$ received 4-6 sessions and 9 patients $(39.1 \%)$ received more than 6 sessions (Table 3). Intravesical doxorubicin used in 13 cases (56.5\%), mitomycin $\mathrm{C}$ in 6 cases $(26.1 \%)$ and 3 patients $(13.0 \%)$ received both drugs (through multiple courses).while 1 patient (4.3\%) received no chemotherapy(Table 3). Thirteen strictures $(56.5 \%)$ were managed by optical urethrotomy while 10 cases $(43.5 \%)$ were mild strictures and opened just by introducing the cystoscope.

\section{Correlations}

The incidence and severity of urethral strictures according to patients' age are shown in Table (6). The incidence and severity of strictures according to the number of cystoscopies done to the point prior to the occurence of stricture are shown in Table (7). 
The correlation of strictures with benign prostatic hypertrophy shown in Table (8). The incidence and severity of stricture according to the number of sessions and type of intravesical chemotherapy received prior to the occurence of stricture shown in Table (9). Type of the treatment procedure used according to the severity of stricture shown in Table (10).

Table (1): Incidence of stricture according to age group

\begin{tabular}{|c|c|c|}
\hline Age (years) & $\begin{array}{c}\text { No } \\
\text { Cases of stricture }\end{array}$ & $\%$ \\
\hline$<50$ & 3 & 13.0 \\
\hline $50-59$ & 9 & 39.1 \\
\hline $80-69$ & $\overline{5}$ & 21.7 \\
\hline$=>70$ & 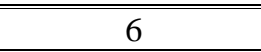 & 26.1 \\
\hline Mean \pm SD (Range) & $59.30 \pm 10.58$ & $38-75$ \\
\hline
\end{tabular}

Table (2): Incidence of stricture in correlation to no. of cystoscope

\begin{tabular}{|c||c||c|}
\hline Number of cystocsope & No & $\%$ \\
\hline \hline Once & 13 & 56.5 \\
\hline \hline Twice & 6 & 26.1 \\
\hline \hline Three\& more & 4 & 17.4 \\
\hline Mean \pm SD (Range) & $1.70 \pm 1.02$ & $1-5$ \\
\hline
\end{tabular}

Table (3): Incidence of stricture in correlation to No. of sessions of chemotherapy

\begin{tabular}{|c|c|c|}
\hline $\begin{array}{c}\text { Number of } \\
\text { sessions }\end{array}$ & No & $\%$ \\
\hline \hline $1-3$ & 4 & 17.4 \\
\hline \hline $4-6$ & 10 & 43.5 \\
\hline \hline$>6$ & 9 & 39.1 \\
\hline \hline Mean \pm SD (Range) & $8.35 \pm 5.20$ & $0-18$ \\
\hline \hline Chemotherapy Doxorubicin & 13 & 56.5 \\
\hline \hline Mitomycin & 6 & 26.1 \\
\hline \hline Both & 3 & 13.0 \\
\hline No & 1 & 4.3 \\
\hline
\end{tabular}

Table (4): Associated BPH and urine retention

\begin{tabular}{|c|c|c|}
\hline & No & $\%$ \\
\hline Benign & 14 & $60.9 \%$ \\
\hline No & 9 & $39.1 \%$ \\
\hline Urine retention Yes & 7 & $30.4 \%$ \\
\hline No & 16 & $69.6 \%$ \\
\hline
\end{tabular}

Table (5): Correlation of severity of stticure

\begin{tabular}{||c||c||c||}
\hline Degree of severity & No & $\%$ \\
\hline \hline Mild & 10 & 43.5 \\
\hline \hline Moderate & 6 & 26.1 \\
\hline Severe & 7 & 30.4 \\
\hline
\end{tabular}


The Incidence and Management of Urethral Stricture in Bladder Carcinoma

Table (6): Correlation of sevrerity of stricture and age group

\begin{tabular}{|c|c|c|c|c|c|c|c|c|}
\hline & \multicolumn{2}{|c|}{ Mild } & \multicolumn{2}{|c|}{ Moderate } & \multicolumn{2}{|c|}{ Severe } & \multirow{2}{*}{$\begin{array}{c}\mathrm{P} \\
\text { value }\end{array}$} \\
\hline & & $\mathrm{No}$ & $\%$ & $\mathrm{No}$ & $\%$ & No & $\%$ & \\
\hline Age (years) & $<<50$ & 1 & $33.3 \%$ & 1 & $33.3 \%$ & 1 & $33.3 \%$ & \multirow{4}{*}{0.624} \\
\hline $50-59$ & & 3 & $33.3 \%$ & 2 & $22.2 \%$ & 4 & $44.4 \%$ & \\
\hline $60-69$ & & 4 & $80.0 \%$ & 1 & $20.0 \%$ & - & - & \\
\hline$=>70$ & & 2 & $33.3 \%$ & 2 & $33.3 \%$ & 2 & $33.3 \%$ & \\
\hline Mean \pm SD & & \multicolumn{2}{|c|}{$58.30 \pm 10.38$} & \multicolumn{2}{|c|}{$61.33 \pm 11.41$} & \multicolumn{2}{|c|}{$59.00 \pm 11.58$} & 0.865 \\
\hline
\end{tabular}

* The Pearson Chi-Square statistic is significant at the 0.05 level for percentages and ANOVA test for comparing means

Table (7): Correlation of severity of stricture and No, of session of cystoscope

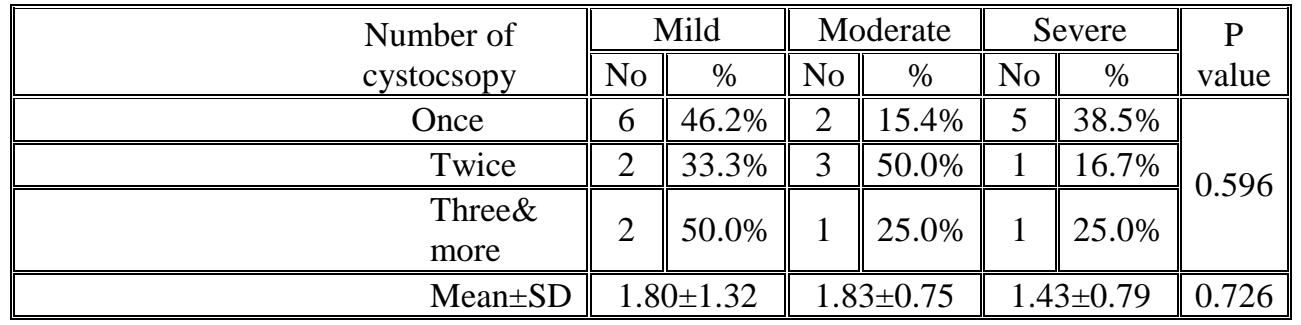

* The Pearson Chi-Square statistic is significant at the 0.05 level for percentages and ANOVA test for comparing means

Table (8): Correlation of severity of stricture and associated BPH urine retention

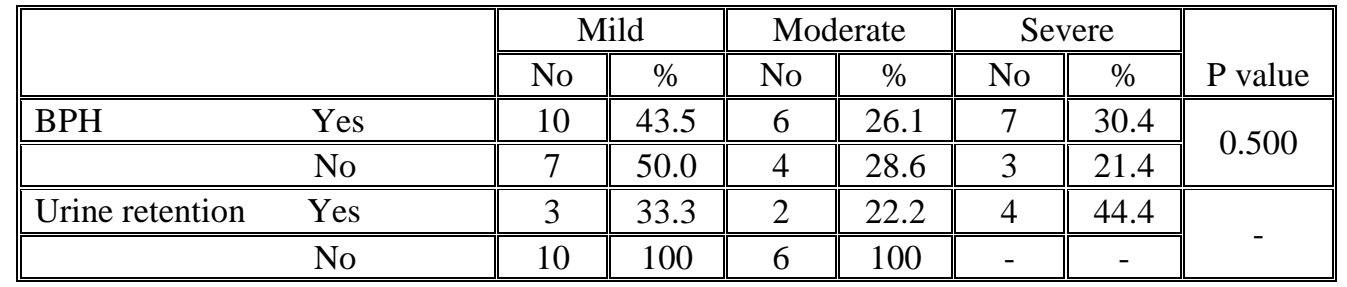

* The Pearson Chi-Square statistic is significant at the 0.05 level

Table (9): Correlatoin of severity of stricure and No. of sessions

\begin{tabular}{|c|c|c|c|c|c|c|c|}
\hline & \multicolumn{2}{|c|}{ Mild } & \multicolumn{2}{|c|}{ Moderate } & \multicolumn{2}{|c|}{ Severe } & \multirow[b]{2}{*}{$\mathrm{P}$ value } \\
\hline & No & $\%$ & No & $\%$ & No & $\%$ & \\
\hline Number of sessions $1-3$ & $\overline{11}$ & 25.0 & - & - & 3 & 75.0 & \multirow{3}{*}{0.301} \\
\hline $4-6$ & 5 & 50.0 & 3 & 30.0 & 2 & 20.0 & \\
\hline$>6$ & 4 & 44.4 & 3 & 33.3 & 2 & 22.2 & \\
\hline Mean \pm SD & \multicolumn{2}{|c|}{$9.00 \pm 5.83$} & \multicolumn{2}{|c|}{$9.00 \pm 3.29$} & \multicolumn{2}{|c|}{$6.86 \pm 5.96$} & 0.682 \\
\hline Chemotherapy Doxorubicin & 4 & 30.8 & 5 & 38.5 & 4 & 30.8 & \multirow{4}{*}{0.678} \\
\hline Mitomycin & 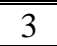 & 50.0 & $\overline{1.1}$ & 16.7 & 2 & 33.3 & \\
\hline Both & 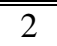 & 66.7 & - & 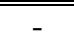 & $\overline{11}$ & 33.3 & \\
\hline No & 1 & 100 & - & - & - & - & \\
\hline
\end{tabular}

* The Pearson Chi-Square statistic is significant at the 0.05 level for percentages and ANOVA test for comparing means

Table (10): Treatment procedure according to severity

\begin{tabular}{||c||c||c||c||c||c||c||c||}
\hline \multirow{2}{*}{ Treatment procedure } & \multicolumn{2}{|c|}{ Mild } & \multicolumn{2}{c||}{ Moderate } & \multicolumn{2}{c|}{ Severe } & \multicolumn{1}{c||}{$\begin{array}{c}\text { P } \\
\text { value }\end{array}$} \\
\cline { 2 - 8 } & No & $\%$ & No & $\%$ & No & $\%$ & \\
\hline Opened by scope & 10 & 100 & - & - & - & - & \\
\hline Optical urethrotomy & - & - & 6 & 100 & 7 & 100 & - \\
\hline
\end{tabular}




\section{Discussion}

Of iatrogenic urethral injury which may end in urethral stricture formation. The Occurence of a urethral stricture in a patient with a superficial bladder tumor will add more to the patient's burden and will make the management and follow-up procedures (which all depend on the urethral access to the bladder)more difficult. Moreover ,there is also a possibility of reimplantation of tumor cells at the site of urethral injury and the dissemination of tumor cells through the suprapubic cystostomy tract needed in case of retention (this may shifting the tumor to an advanced stage). The aim of this study (which to our knowledge is the first in this aspect) is to elicit the real size of this important clinical problem in our practice, and to study all the possible etiological factors and their impact on the severity of stricture. We find an incidence of 23,5\% urethral stricture in 98 patients we followed them for 2 years, however, this study was unable to clarify the exact cause of the stricture ,the patients underwent frequent urological intervention and it is impossible to determine the exact cause of the stricture. In the age group below 50 years we find 1 case (33.3\%) had a mild stricture, 1 case $(33.3 \%)$ had moderate one and 1 case $(33.3 \%)$ had severe stricture. In the age group 50-59 years 3 cases $(33.3 \%)$ were mild , 2 cases $(22.2 \%)$ had moderate stricture and 4 cases $(44.4 \%)$ had sever one. In the age group 60-69 years 4 cases $(80.0 \%)$ had mild stricture, 1 case (20.0\%) had moderate stricture. In the age group above 70 years 2 cases $(33.3 \%)$ had mild stricture, 2 cases $(33.3 \%)$ had moderate stricture,and 2 cases $(33.3 \%)$ had sever one Table (6). In a patent subjected to only one cystoscope 6 cases $(46.2 \%)$ had mild stricture , 2 cases $(15.4 \%)$ had moderate stricture and 5 cases $(38.5 \%)$ had severe one. In the group subjected to 2 cystoscope before the occurance of stricture 2 cases $(33.3 \%)$ had mild stricture, 3 cases $(50.0 \%)$ had moderate stricture and only 1 case (16.7\%) had sever stricture. In the group subjected to $3 \&$ more cystoscope 2 cases (50.0\%) had mild stricture, 1 case $(25.0 \%)$ had moderate and 1 case $(25.0 \%)$ had severe one Table (7). In patients suffering from Bbenign prostatic hypertrophy 10 cases $(43.5 \%)$ had mild stricture, 6 cases $(26.1 \%)$ had moderate stricture, while 7 cases $(30.4 \%)$ had severe one. In patients with no brnign prostatic hypertrophy 7 cases $(50.0 \%)$ had mild stricture , 4 cases $(28.6 \%)$ had moderate stricture and 3 cases $(21.4 \%)$ had severe one. In patients suffering from urine retention 3 cases (33.3\%) had mild stricture , 2 cases (22.2\%) had moderate stricture while 4 cases (44.4\%) had sever one. Table (8). In the group who receive 1-3 sessions of chemotherapy 1 case $(25.0 \%)$ had mild stricture, while 3 cases $(75.0 \%)$ had severe stricture. In the group receiving 4-6 sessions of chemotherapy 5 cases $(50.50 \%)$ had mild stricture ,3 cases (30.3\%) had moderate stricture and 2 cases (20.0\%) had sever one. In the group receiving more than 6 sessions of chemotherapy 4 cases $(44.4 \%)$ had mild stricture, 3 cases $(33.3 \%)$ had moderate stricture and 2 cases $(22.2 \%)$ had severe one Table (9). Regarding type of chemotherapy in patient receiving doxorubicin 4 cases (30.8\%) had mild stricture, 5 cases $(38.5 \%)$ had moderate stricture and 4 cases $(30.8 \%)$ had severe one. In patients receiving 
mitomycin 3 cases $(50.0 \%)$ had mild stricture , 1 case $(16.7 \%)$ hade moderate stricture and 2 cases $(33.3 \%)$ had severe one. In patients receiving both types of chemotherapy 2 cases $(66.7 \%)$ had mild stricture and 1 case $(33.3 \%)$ had severe one. We have one case receiving no chemotherapy had mild stricture Table (9). Regarding the treatment procedures all the 10 cases opened just by introducing the cystoscope were mild. In patients treated by optical urethrotomy we have 6 cases $(100 \%)$ had moderate stricture and 7 cases $(100 \%)$ had severe stricture Table (10).

\section{Conclusions}

Urethra stricture in patients with bladder carcinoma may be a substantial source of preventable morbidity, implementing a nursing education program may significantly decrease the incidence of stricture ,the urologist should assume a leadership role in promoting catheter safety.

\section{Recommendations}

The urologist themselves should take more care during insertion of the scope and use suffitiont amount of lubricant .

\section{References}

[1]Chiou RK, Matamoros A, Anderson JC and Taylor RJ: Changing concepts of urethral stricture managements I: assessment of urethral stricture disease . Nebr Med J 1996;81 282.

[2]Webster GD, Koefoot RB and Sihelnik SA:urethroplasty management in 100 cases of urethral stricture : a rationale for procedure selection. J Uro 1985;134:892.

[3]Ashken et al., 1991. Ashken MH, Coulange C, Milroy EJ, et al: European experience with the urethral Wallstent for urethral strictures. Eur Urol 1991; 1:181.

[4]Koraitim, 1997. Koraitim M: Posttraumatic posterior urethral strictures in children: A 20-year experience. J Urol 1997; 157:641-645.

[5] Aboseif et al., 1989. Aboseif SR, Breza J, Lue TF, Tanagho EA: Penile venous drainage in erectile dysfunction: Anatomical, radiological and functional.

[6]Bogaraz, 1936. Bogaraz NA: Plastic restoration of the penis. Sovet Khir 1936; 8:303-307.

[7]Kizer and Morey, 2005. Kizer WS, Morey AF: Proximal bulbar urethroplasty via extended anastomotic approach: What are the limits [abstract 87].

[8]Koraitim, 1985. Koraitim M: Experience with 170 cases of posterior urethral stricture during 7 years. J Urol 1985; 133:408-410.

[9]Jordan, 1997. In: Jordan GH, ed. Reconstruction for urethral stricture. Atlas of Urologic Clinics of North America, vol 5. Philadelphia: WB Saunders; 1997

[10]Barbagli et al., 1995. Barbagli G, Menghetti I, Azzaro F: A new urethroplasty for bulbous urethral strictures. Acta Urol Ital 1995; 9:313-317.

[11] Bryden and Gough, 1999. Bryden AA, Gough DC: Traumatic urethral diverticula. BJU Int 1999; 84:885-886. 